\title{
可见光/有机小分子协同催化选择性氧化硫醚化合物
}

\author{
金伟伟 刘晨江* \\ (新疆大学化学学院 乌鲁木齐 830046)
}

\section{Synergistic Visible Light Catalysis/Organocatalysis for Selective Oxidation of Sulfides}

\author{
Jin, Weiwei Liu, Chenjiang* \\ (College of Chemistry, Xinjiang University, Urumqi 830046)
}

含硫有机化合物具有多种氧化态, 因此其在精细化 工、医药和材料科学领域有着广泛应用 ${ }^{[1]}$. 在常见的含 硫化合物中, 亚砜和砜是多种合成药物、天然产物和先 进有机材料中是必不可少的结构单元 ${ }^{[2]}$. 对于精细化工 和药物工业, 从生产成本和操作方便的角度考虑, 从同 一原料出发选择性可调地合成不同类型的高附加值化 学品无疑是最理想的合成途径.

在过去几十年, 科学家致力于发展以廉洁易得的硫 醚化合物为原料, 选择性合成亚砜和砜类化合物的方 法. 2012 年, 南开大学何良年课题组 ${ }^{[3]}$ 率先报道了在加 热条件下使用化学计量的过氧硫酸氢钾复合盐实现了 选择性氧化硫醚的反应(Scheme 1, a). 新疆大学刘晨江 课题组 ${ }^{[4]}$ 和湖南科技学院何卫民课题组 ${ }^{[5]}$ 分别独立报道 了以分子氧作为氧源, 温度控制的硫醚选择性氧化反应 (Scheme 1, b). 但是, 在高温条件下以氧气为氧化剂使 用易燃的有机溶剂可能会引起潜在的火灾和爆炸, 从而
大大限制其在工业上的应用. 近年来，以氧气为唯一氧 化剂的可见光诱导的氧化反应已经成为合成化学的重 要组成部分, 成为传统热反应过程的有益补充. ${ }^{[6]} 2019$ 年华东师范大学姜雪峰 ${ }^{[7]}$ 实现了可见光诱导铀盐催化硫 醚的选择性氧合反应(Scheme 1, c). 最近, 东京大学 Suzuki 和 Yamaguchi 等 ${ }^{[8]}$ 报道了可见光诱导四苯基膦十 钒酸盐催化硫醚可调的氧合反应(Scheme 1,d). 但是在 上述光催化过程中需要使用昂贵的铀盐催化剂和商业 不可得的 TPPV10 纳米催化剂, 这不仅增加了生产成本 而且在最终产物中可能带来过渡金属残留问题. 当前, 已发展的硫醚类化合物选择性可调的氧化反应通常依 赖于不同的反应介质，不仅增加反应操作难度，还增加 反应成本. 因此, 从环境和经济的角度考虑, 发展以氧 气为氧源, 廉价易得的非金属试剂为光催化剂的可见光 诱导的硫醚可调的绿色氧化反应对药物工业是十分必 要的.

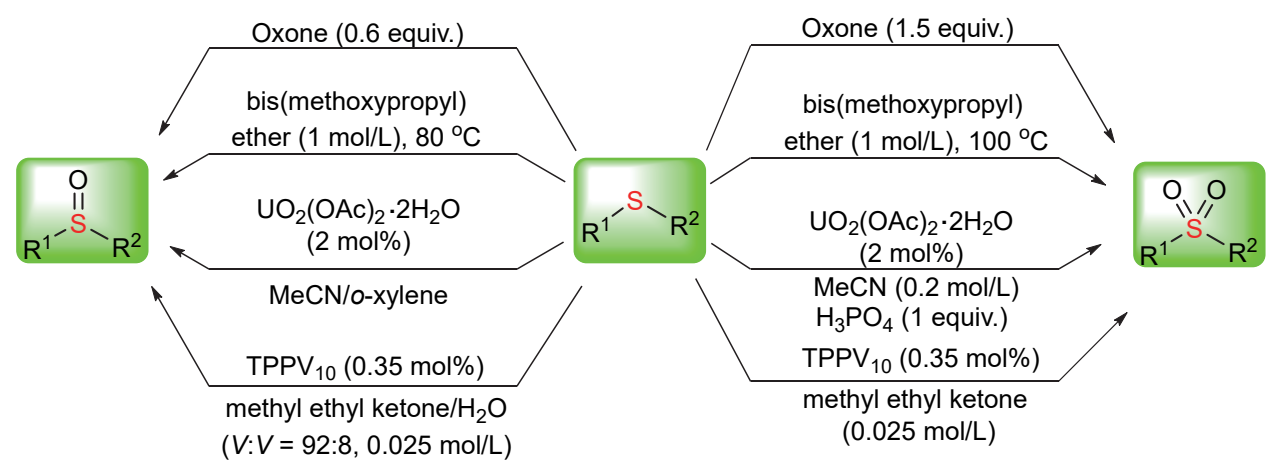

(a)

(b)

图式 1 选择性可调的硫醚需氧氧化反应

Scheme 1 Selective switchable aerobic oxidation of sulfides

*Corresponding author. E-mail: pxylcj@126.com. Published online April 28, 2021. 
近日, 湖南科技学院化学与生物工程学院何卫民课 题组 ${ }^{[9]}$ 在其前期有关硫醚选择性氧化课题的基础上，以 分子氧为氧源, 廉价易得的三氟甲基亚磺酸钠为光催化 剂, 二乙二醇二丁醚为促进剂和共催化剂, 二者协同催 化实现了硫醚的高选择性需氧氧化制备亚砜和砜 (Scheme 2).

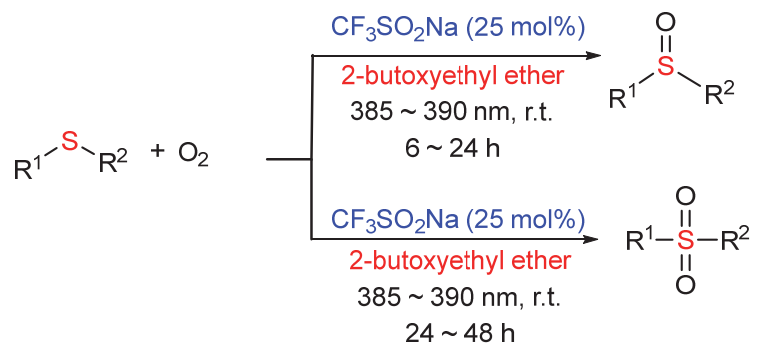

图式 2 协同催化硫醚选择性氧化

Scheme 2 Synergistic catalysis for selective oxidation of sulfides

作者以 4-甲基苯甲硫醚为模型底物, 通过系统的条 件笁选, 发现二乙二醇二丁醚的用量是影响催化体系氧 化能力的关键因素, 降低溶剂用量至 4 equiv. 时显著提 高了该催化体系的氧化能力. 通过控制反应时长分别以 91\%(6 h) 和 100\% (24 h) 的分离收率得到氧化产物亚砜 和砜. 控制实验表明可见光、三氟甲基亚磺酸钠和二乙 二醇二丁醚三者缺一不可.

在最佳反应条件下，作者对底物适用范围进行了考 察. 研究表明, 反应具有很好的官能团兼容性, 苯环上 连有各种给电子取代基(甲基、甲氧基)和吸电子取代基 (氟、氯、溴、乙酰基、酯基、氰基)的苯甲硫醚都可以 以中等到优秀的收率得到目标产物. 取代苯甲硫醚的电 子效应和位阻效应对氧化过程没有显著影响. 各种双芳 基、芳基杂芳基硫醚也可以很好地兼容.

含亚砜和砜片段的药物分子及其衍生物也可以通 过后期修饰以良好的收率方便地制备(72\% 84\%)(图 1). 进一步证实了该方法的实用性和潜在的应用价值.

机理验证实验表明该反应可能经过自由基历程. 在 可见光诱导下, 三重态氧氧化三氟甲基亚磺酸钠形成五 配位硫化物, 然后光照产生其激发态. 激发态经单电子 转移一方面与硫醚形成硫阳离子自由基, 另一方面与氧 气形成五配位氧自由基中间体和活泼的超氧阴离子自 由基. 接下来前者被超氧阴离子自由基氧化生成亚砜. 后者则与溶剂发生夺氢产生碳中心自由基, 进一步与超 氧阴离子自由基作用将亚砜氧化成砜.

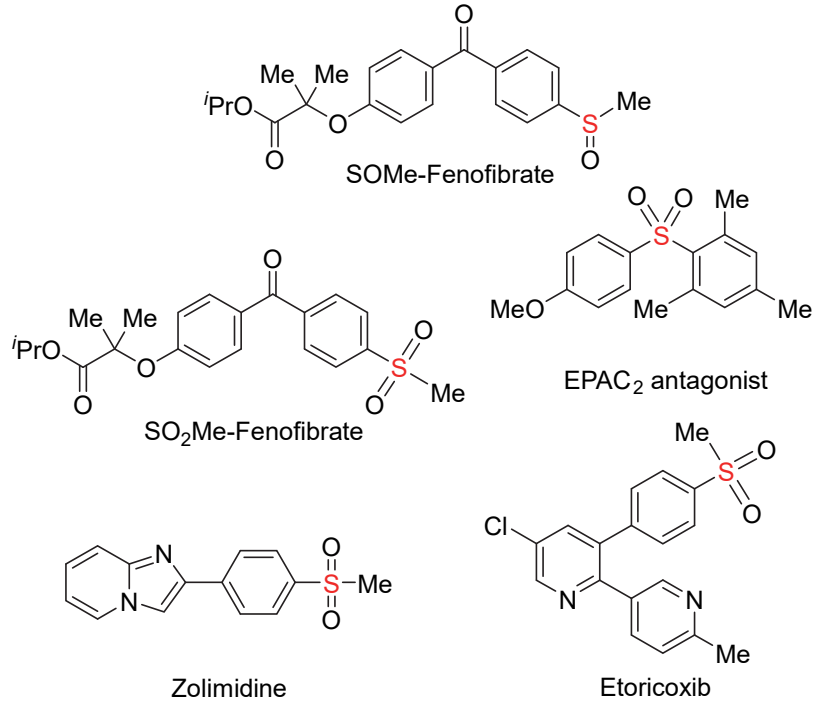

图 1 药物活性分子后修饰

Figure 1 Late stage modification of pharmaceutical active molecules

总之，何卫民等基于协同催化效应，发展了可见光 诱导的硫醚选择性可调的需氧氧化反应，该催化体系具 有所有试剂均商业可得且价格低廉、实验操作简便、安 全性好、环境友好、无需任何过渡金属催化剂和助剂及 溶剂用量极少等优点, 在温和条件下仅通过改变反应时 间就可以实现亚砜和砜类化合物的选择性调变和高效 制备. 通过对药物活性分子的后期修饰证明该方法没有 重金属残留的风险，在药物合成领域有潜在应用. 与已 有的光催化方法相比，简化了操作步骤并降低了生产成 本，是一种非常实用的可见光诱导的需氧氧化反应，符 合绿色化学的发展要求.

\section{References}

[1] Scott, K. A.; Njardarson, J. T. Top. Curr. Chem. 2018, 376, 5.

[2] Simpkins, N. S. Sulfones in Organic Synthesis, Pergamon Press, Oxford, 1993.

[3] Yu, B.; Liu, A.-H.; He, L.-N.; Li, B.; Diao, Z.-F.; Li, Y.-N. Green Chem. 2012, 14, 957.

[4] Cheng, Z.; Sun, P.; Tang, A.; Jin, W.; Liu, C. Org. Lett. 2019, 21, 8925.

[5] Liu, K.-J.; Deng, J.-H.; Yang, J.; Gong, S.-F.; Lin, Y.-W.; He, J.-Y.; Cao, Z.; He, W.-M. Green Chem. 2020, 22, 433.

[6] Liang, Y.; Wei, J.; Qiu, X.; Jiao, N. Chem. Rev. 2018, 118, 4912

[7] Li, Y.; Rizvi, S. A.-E.-A.; Hu, D.; Sun, D.; Gao, A.; Zhou, Y.; Li, J.; Jiang, X. Angew. Chem., Int. Ed. 2019, 58, 13499.

[8] Li, C.; Mizuno, N.; Murata, K.; Ishii, K.; Suenobu, T.; Yamaguchi, K.; Suzuki, K. Green Chem. 2020, 22, 3896.

[9] Liu, K.-J.; Wang, Z.; Lu, L.-H.; Chen, J.-Y.; Zeng, F.; Lin, Y.-W.; Cao, Z.; Yu, X.; He, W.-M. Green Chem. 2021, 23, 496.

(Zhao, C.) 